\title{
Comparison of Teneligliptin and Atorvastatin on Lipid Profile in Patients with Type 2 Diabetes Mellitus
}

\author{
V Vyshnavi ${ }^{1}$, T Supriya ${ }^{1}$, Bandaru Siva Subrahmanyam², Eggadi Venkateshwarlu, Bandaru Sheshagiri and \\ Sharvana Bhava ${ }^{1}$ \\ ${ }^{1}$ Department of Clinical Pharmacy, Vaagdevi College of Pharmacy, Warangal, Telangana, India \\ ${ }^{2}$ Sri Bhadrakali Diabetic Clinic, Naimnagar, Hanamkonda, Warangal, Telangana, India
}

Submission: March 27, 2018; Published: August 08, 2018

*Corresponding author: Eggadi Venkateshwarlu, Bandaru Sheshagiri Sharvana Bhava, Department of Clinical Pharmacy, Vaagdevi College of Pharmacy, Warangal, India, Email: sharavanabhava6@gmail.com

\begin{abstract}
Diabetes mellitus is a chronic metabolic disease characterized by hyperglycemia resulting from defects in insulin secretion, insulin action or both which results in long term damage, dysfunction and failure of various organs especially eyes, kidneys, nerves, heart and blood vessels. The efficacy of Teneligliptin and Atorvastatin on lipid profiles in patients with type 2 Diabetes mellitus were compared. This study was designed to evaluate the efficacy of these two drug regimens.
\end{abstract}

Material and methods: Males and females of 25-90 years diagnosed with type 2 Diabetes mellitus are included in our study.

Results: 275 patients were recruited for our study. 47 were excluded because of their inability to attend or participate and did not meet inclusion criteria. $229 \mathrm{~T} 2 \mathrm{DM}$ patients who were taking Teneligliptin $20 \mathrm{mg}$ once daily or Atorvastatin $20 \mathrm{mg}$ once daily completed the study. There were significant decrease in the levels of TC, HDL, LDL, TG, VLDL in Teneligliptin and Atorvastatin are 35.1, 4.1, 14.8, 37, 7.5(mg/dl) and 35.1, 4, $14.6,37.1,7.6(\mathrm{mg} / \mathrm{dl})$ respectively.

Conclusion: From this study we conclude that Teneligliptin $20 \mathrm{mg}$ and Atorvastatin 20mg have proved to have similar efficacy on the lipid profiles. Hence we conclude that Teneligliptin is an efficacious drug for T2 DM patients in management of glycemic control and lowering lipid profiles.

\section{Background and Aim}

Diabetes mellitus is a group of metabolic diseases which challenges the global population. Thus, there is an increasing need to conduct research in this field [1,2]. The aim of the study is to compare the efficacy of Teneligliptin and Atorvastatin on lipid profile of patients with T2 DM. Comparative evidence is required to guide appropriate therapy to attain lipid control and prevent complications of diabetes $[3,4]$.

\section{Material and Methods}

It is a prospective, observational, comparative study conducted in patients from "Sri Bhadrakali Diabetic Clinic" located at Naimnagar, Hanamkonda. Patients were explained about the study \& informed consent forms were seeked by explaining them in their local language [5,6]. Institutional Human Ethical Committee Endorsement was obtained after submission of protocol and IHEC No. is MGM/VCOP/PHARMD/V/017/2017.

\section{Inclusion criteria}

Males and females of 25-90 years diagnosed with type 2 Diabetes mellitus will be included in our study.

\section{Exclusion criteria}

Pregnant and lactating females, patients on insulin therapy, history of type1 Diabetes mellitus, signs of diabetic complications (neuropathy, nephropathy and retinopathy) are to be excluded [7]. Patients with clinical signs and symptoms of acute myocardial infarction, liver failure, chronic heart failure, and hypertension are to be excluded.

\section{Study design}

It is a prospective, observational, comparative study design, and the patients who were taking Teneligliptin $20 \mathrm{mg}$ and Atorvastatin $20 \mathrm{mg}$ were included [8]. 


\section{Current Research in Diabetes \& Obesity Journal}

\section{Clinical response assessment}

The efficacy of Teneligliptin and Atorvastatin was assessed by measuring the change in the HbA1c, Fasting blood glucose, Post prandial blood glucose and Lipid profile levels after 12 weeks of treatment.

Primary end was change in HbA1c levels, FBS, PLBS levels at 12 weeks as compared to the baseline levels in both the groups [9].

The secondary end point was change in lipid profile levels such as serum cholesterol, high density lipoproteins, low density lipoprotein, triglycerides and very low-density lipoprotein which were measured at 12 weeks as compared to baseline levels [10].

\section{Statistical analysis}

All parameters were expressed as mean \pm SD. Data analyses was performed using the GRAPH PAD PRISM 5.0. One way ANNOVA was used to assess significant differences between values obtained before and 3 months after the addition of Atorvastatin and Teneligliptin (Figure 1).

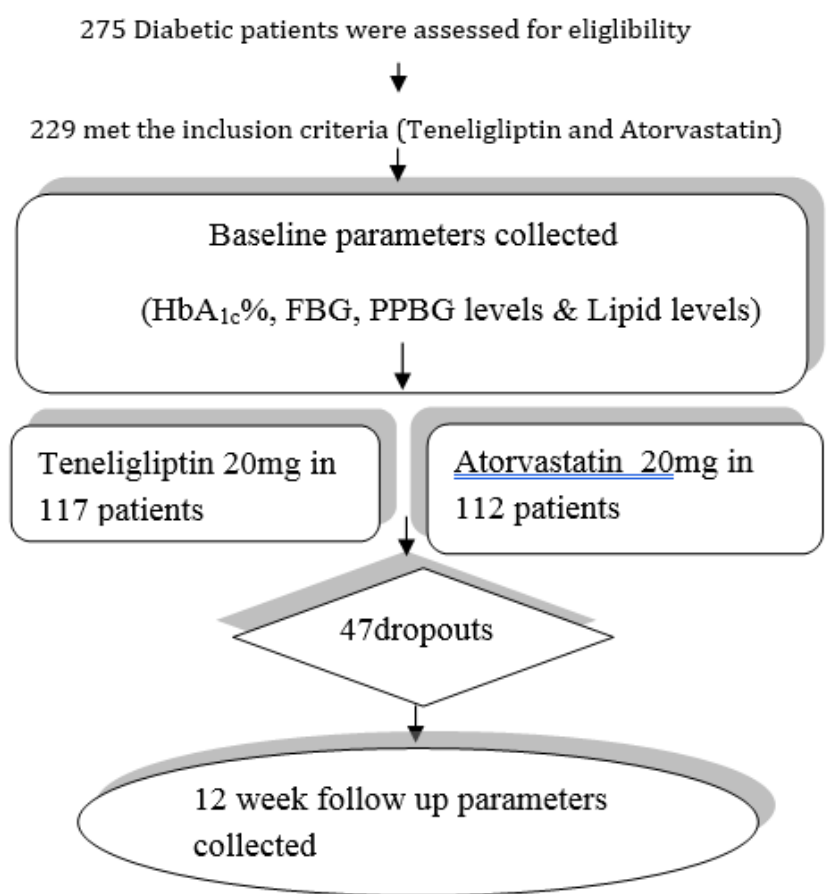

Figure 1: Total number of patients completed the study.

\section{Results}

\section{High density lipoproteins (Figure 2)}



Figure 2: Mean change in HDL of 2 drugs, at visit 1, visit 2 and visit 3. 


\section{Current Research in Diabetes \& Obesity Journal}

Mean change in high density lipoprotein for Teneligliptin was $39.3 \pm 14.4 \mathrm{mg} / \mathrm{dl}$.
Mean change in high density lipoprotein for Atorvastatin was $39.3 \pm 34.8 \mathrm{mg} / \mathrm{dl}$.

\section{Total cholesterol (Figure 3)}

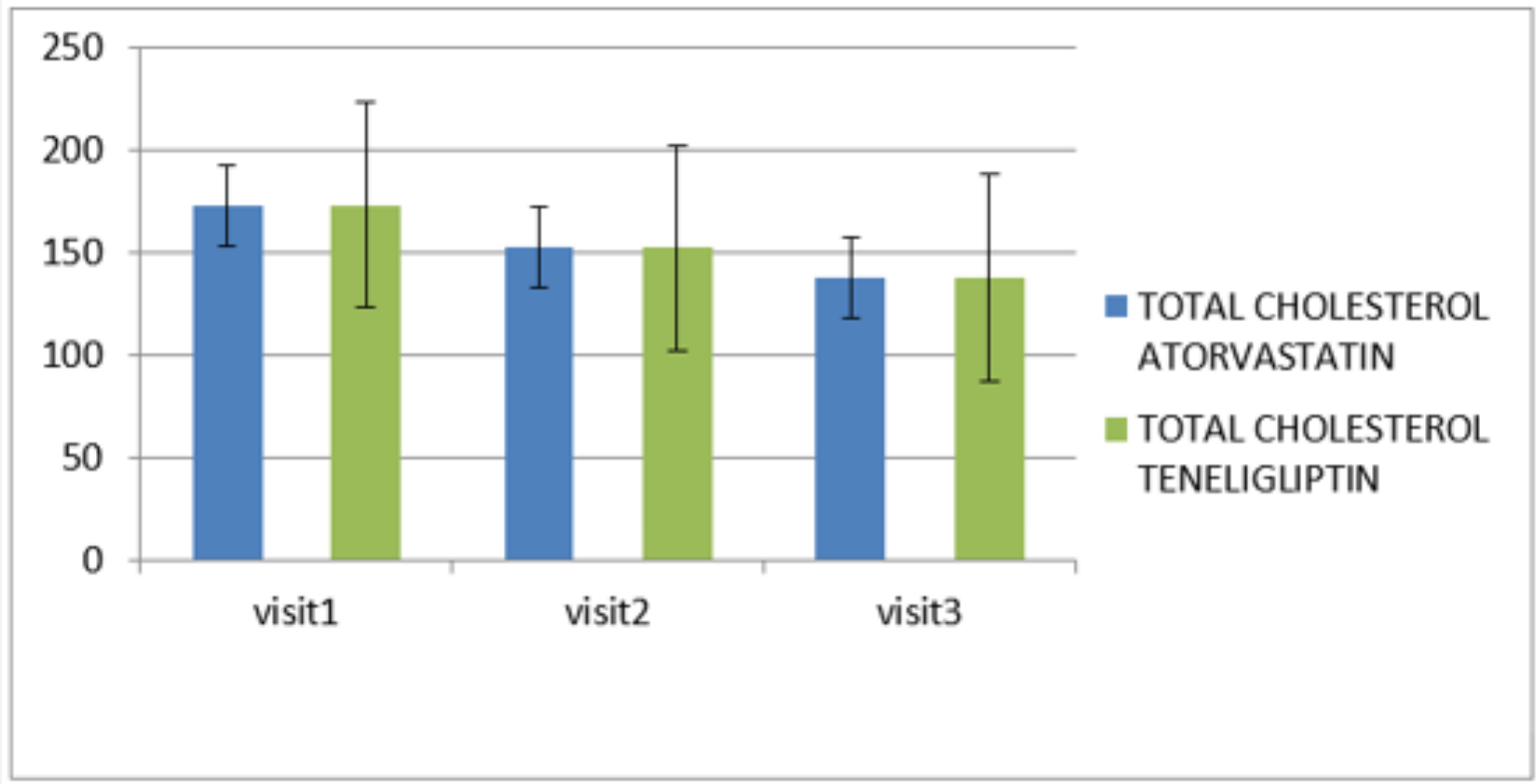

Figure 3: Mean change in total cholesterol of 2 drugs, at visit 1, visit 2 and visit 3.

Mean change in total cholesterol for Teneligliptin was $172.6 \pm 80.5 \mathrm{mg} / \mathrm{dl}$.
Mean change in total cholesterol for Atorvastatin was $172.7 \pm 86.5 \mathrm{mg} / \mathrm{dl}$.

\section{Low density lipoproteins (Figure 4)}

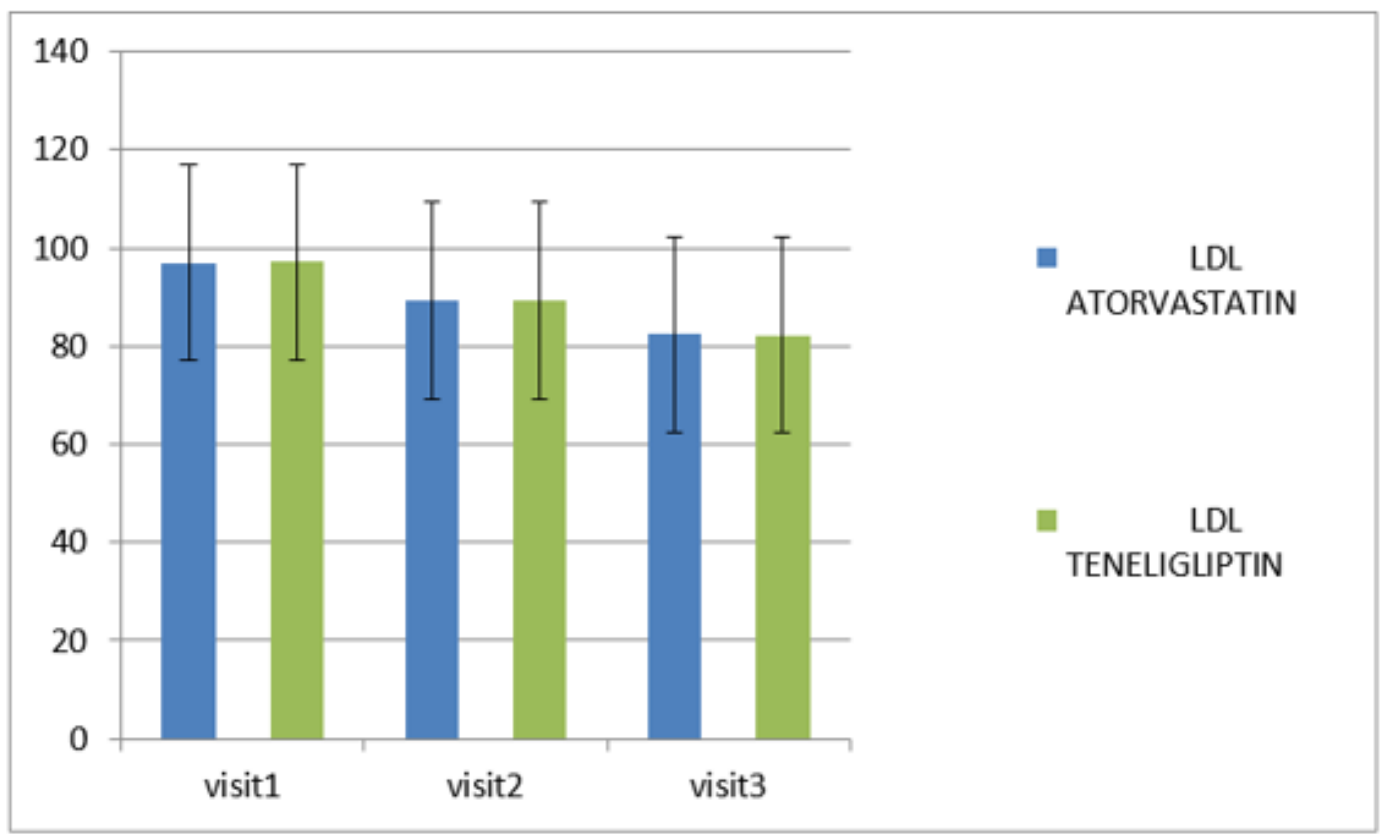

Figure 4: Mean change in low density lipoprotein of 2 drugs, at visit 1, visit 2 and visit 3.

Mean change in low density lipoprotein for Teneligliptin was $97.1 \pm 33 \mathrm{mg} / \mathrm{dl}$.
Mean change in low density lipoprotein for Atorvastatin was $97 \pm 36 \mathrm{mg} / \mathrm{dl}$ 


\section{Current Research in Diabetes \& Obesity Journal}

\section{Triglycerides (Figure 5)}

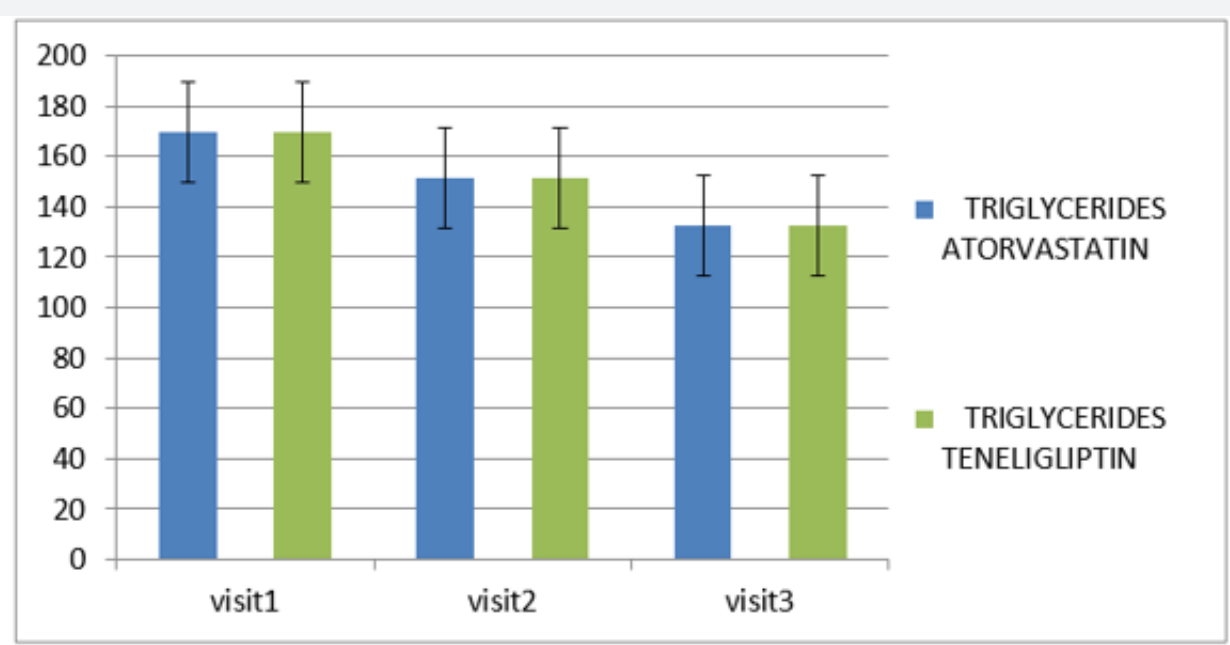

Figure 5: Mean change in triglycerides of 2 drugs, at visit 1, visit 2 and visit 3.

Mean change in triglycerides for Teneligliptin was $169.4 \pm 83.8 \mathrm{mg} / \mathrm{dl}$.
Mean change in triglycerides for Atorvastatin was $169.5 \pm 67.4 \mathrm{mg} / \mathrm{dl}$.

\section{Very low-density lipoproteins (Figure 6)}

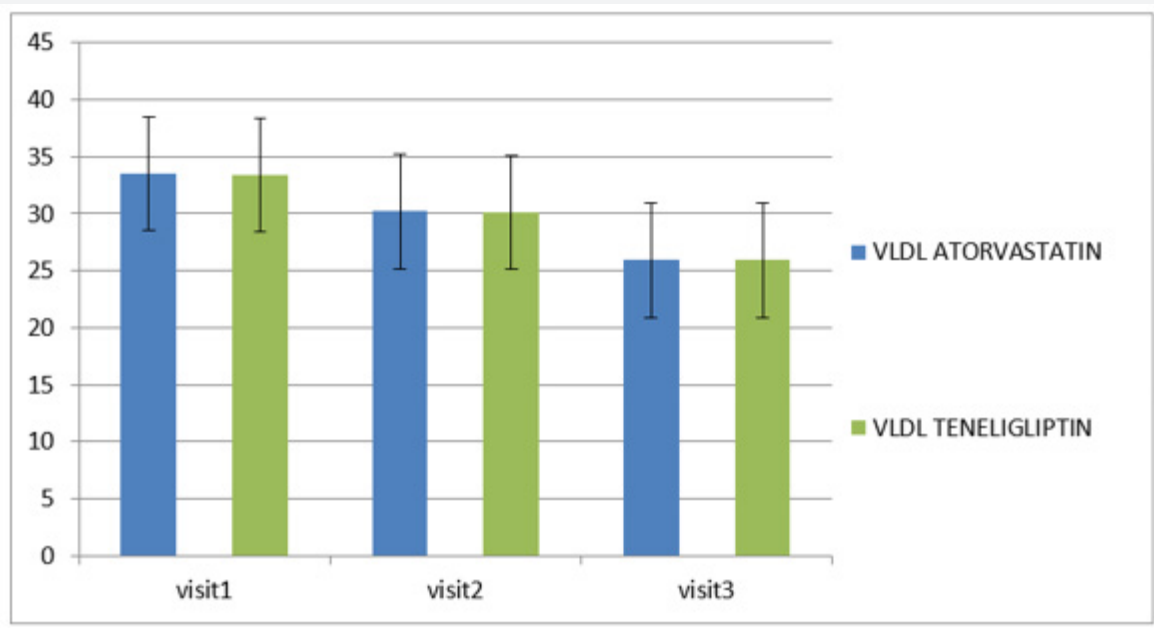

Figure 6: Mean change in very low-density lipoproteins of 2 drugs, at visit 1, visit 2 and visit 3.

Mean change in low density lipoprotein for Teneligliptin was $33.4 \pm 13.2 \mathrm{mg} / \mathrm{dl}$.

Mean change in low density lipoprotein for Atorvastatin was $33.5 \pm 11.9 \mathrm{mg} / \mathrm{dl}$.

\section{Discussion}

Comparison of Teneligliptin $20 \mathrm{mg}$ and Atorvastatin $20 \mathrm{mg}$ was done on lipid profile of patients with $\mathrm{T}_{2}$ Diabetes mellitus. The following changes in glycemic parameters like $\mathrm{HbA}_{1} \mathrm{c}$, FBS, PLBS and lipid profile (TC, HDL, LDL, TG, VLDL) were observed. In this study, Teneligliptin or Atorvastatin therapy from baseline to visit3 has provided a greater reduction in $\mathrm{HbA}_{1} \mathrm{c}$ i.e., Teneligliptin (1\%) and Atorvastatin (1.5\%). In the study [7], a similar decrease in $\mathrm{HbA}_{1} \mathrm{c}$ of $0.57 \%$ were observed. The mean changes in FBS levels from baseline to visit 3 was observed to be $45.8 \mathrm{mg} / \mathrm{dl}$ in Teneligliptin and $45.6 \mathrm{mg} / \mathrm{dl}$ in Atorvastatin. In the randomized, double blind study ( $\mathrm{n}=99$ ) by [8], Teneligliptin $20 \mathrm{mg}$ has showed greater reductions in the values of FBS- $20.7 \mathrm{mg} / \mathrm{dl}$ and $6.9 \mathrm{mg} / \mathrm{dl}$. Comparison of Teneligliptin $20 \mathrm{mg}$ and Atorvastatin $20 \mathrm{mg}$ were done on lipid profile of patients with $\mathrm{T}_{2}$ Diabetes mellitus.

\section{Conclusion}

From this study we conclude that Teneligliptin $20 \mathrm{mg}$ and Atorvastatin $20 \mathrm{mg}$ have proved to have similar efficacy on the lipid profiles. Hence, we conclude that Teneligliptin is an efficacious drug for $\mathrm{T}_{2} \mathrm{DM}$ patients in management of glycemic control and lowering lipid profiles. 


\section{Current Research in Diabetes \& Obesity Journal}

\section{References}

1. Joseph T Dipiro et al, "Pharmacotherapy, a pathophysiologic approach", ( $8^{\text {th }}$ edn) pp:212-215.

2. Yiming Wang (2015) “Diabetes mellitus type 2 Qsota” has included the causes of type-2 Diabetes.

3. Taylor JJ, Preshaw PM, Lalla E (2013) "A review of the evidence for pathogenic mechanisms that may link periodontitis and diabetes". J Clin Periodontol 84: S113-134.

4. Filippova (2004) Methodic materials for international students (IV-VI year).

5. T Kadowaki et al. (2013) "Efficacy and safety of Teneligliptin added to Glimepride in Japanese patients with type 2 Diabetes Mellitus: randomised, double-blind, placebo controlled study with an open label, long-term extension" 16(5):418-425.

6. Abudaker M, Mishra P, Swami OC (2017) “Teneliglipin in management of diabetic kidney disease: a review of place in therapy". J Clin Diagn Res 11(1): OE05-OE09.
7. Pavitra N, Chaitanya MVNL (2015) "A lipid lowering effect of anti diabetic agents recent research". International Journal of Pharma Research \&Review 4(6):73-80.

8. Sagara M, Suzuki K, Aoki C, Tanaka S, Taquchi I, et al. (2016) "Impact of Teneligliptin on oxidative stress and endothelial function in type 2 diabetes patient with chronic kidney disease: a case control study". Cardiovasc Diabetol 15: 76.

9. Fukuda-Tsuru S, Anabuki J, Abe Y, Yoshida K, Ishii S (2012) "A novel, potent, and long-lasting dipeptidyl peptidase-4 inhibitor, teneligliptin,improves postprandial hyperglycemia and dyslipidemia after single and repeated administrations". Eur J Pharmacol 696(13): 194-202

10. Eto T, Inoue S, Kadowaki T (2012) "Effects of once daily teneligliptin on 24-h blood glucose control and safety in Japanese patients with type 2 diabetes mellitus: a 4- week, randomized, double-blind, placebocontrolled trial”. Diabetes Obes Metab 14(11): 1040-1046.

\section{Your next submission with Juniper Publishers} will reach you the below assets

- Quality Editorial service

- Swift Peer Review

- Reprints availability

- E-prints Service

- Manuscript Podcast for convenient understanding

- Global attainment for your research

- Manuscript accessibility in different formats

( Pdf, E-pub, Full Text, Audio)

- Unceasing customer service

Track the below URL for one-step submission https://juniperpublishers.com/online-submission.php 